\title{
A RECEPÇÃO DA POLÍTICA DE ARISTÓTELES NA NOVA ESPANHA: ALONSO DE LA VERA CRUZ E O SEU SPECULUM CONIUGIORUM (1556)
}

The Reception of Aristotle's Politics in New Spain: Alonso de la Vera Cruz and His Speculum Coniugiorum (1556)

La recepción de la Política de Aristóteles len la Nueva España: Alonso de la Vera Cruz y su Speculum Coniugiorum (1556)

Alfredo Storck

Universidade Federal do Rio Grande do Sul, Porto Alegre, RS, Brasil.

\section{Resumo}

Este artigo está dividido em duas partes. Começo por oferecer algumas informações de fundo sobre as discussões e os debates que tiveram lugar na Europa no final da Idade Média e no início dos tempos modernos e que envolveram autoridades políticas e eclesiásticas. Não pretendo ser exaustivo nesta apresentação. Procuro apenas sugerir o contexto mais amplo das disputas entre o poder dos monarcas europeus $\mathrm{e}$ o da Igreja Católica durante os séculos XV, XVI e o início do século XVII. Na segunda parte, trato especificamente da obra de Alonso de la Vera Cruz e utilizo a primeira parte como pano de fundo sobre o qual se pode compreender o pensamento de Frei Alonso. Buscarei sobretudo enfatizar o papel desempenhado pela Política de Aristóteles na concepção de Alonso sobre o casamento na Nova Espanha.

Palavras-chave: Alonso de la Vera Cruz. Escolástica Colonial. Recepção da Política de Aristóteles no Novo Mundo. Casamento na Nova Espanha.

Professor Titular do Departamento de Filosofia da UFRGS. O presente trabalho foi realizado com apoio do CNPq, Conselho Nacional de Desenvolvimento Científico e Tecnológico - Brasil (307054/2017-9).ORCID: https://orcid.org/0000-0002-3046-0812.E-mail:alfredo.storck@ufrgs.br 


\begin{abstract}
This article is divided in two parts. I start by offering some background information about discussions and debates that took place in Europe in the late Middle Ages and early Modern times involving political and ecclesiastical authorities. I do not intend to be exhaustive in this presentation, but I only seek to suggest the broader context of the disputes between the power of the European monarchs and that of the Catholic Church during the 15 th, 16 th and early 17 th centuries. In the second part I deal specifically with the work of Alonso de la Vera Cruz and I use the first part as the background against which Alonso's thought can be understood. I will mainly seek to emphasize the role played by the Politics of Aristotle in Alonso's conception of marriage in New Spain.
\end{abstract}

Keywords: Alonso de la Vera Cruz. Colonial Scholasticism. Reception of the Aristotle's Politics in the New World. Marriage in New Spain.

\title{
Resumen
}

Este artículo se divide en dos partes. Empezo por ofrecer algunas informaciones generales sobre las discusiones y debates que tuvieron lugar en Europa al final de la Edad Media y al comienzo de los tiempos modernos y en los que participaron autoridades políticas y eclesiásticas. No pretendo ser exhaustivo en esta presentación, pero sólo busco sugerir solamente el contexto más amplio de las disputas entre el poder de los monarcas europeos y el de la Iglesia católica durante los siglos XV, XVI y en el comienzo del siglo XVII. En la segunda parte, abordo específicamente de la obra de Alonso de la Vera Cruz y utilizo la primera parte como telón de fondo para el que podemos entender el pensamiento de Frei Alonso. Buscaré, sobretodo, destacar el papel desempeñado por la Política de Aristóteles en la concepción de Alonso sobre el matrimonio en la Nueva España.

Palabras clave: Alonso de la Vera Cruz. Escolástica Colonial. Recepción de la Política de Aristóteles en el Nuevo Mundo. Matrimonio en la Nueva España. 


\section{Introdução²}

Se considerarmos os primeiros anos após a chamada descoberta do Novo Mundo pelas coroas espanholas e portuguesas, podemos constatar a existência de dois projetos coloniais distintos: um primeiro que exprime os interesses políticos das monarquias europeias e um segundo associado ao projeto de catequização desenvolvido pela Igreja Católica. Apesar de amplamente interligados, esses projetos traziam consigo importantes tensões que se manifestavam na forma de lutas diretas de poder entre a Igreja Católica e as monarquias. Comecemos chamando atenção para algo bastante simples, mas fundamental, a saber que a descoberta de novas terras impulsionou o poder das monarquias para fora dos limites da Europa. ${ }^{3}$ Isso trouxe consigo disputas e problemas de justificação do poder em escala global de tal modo que, a partir do século XVI, as disputas entre as monarquias europeias já não eram apenas um problema a ser resolvido internamente ao continente europeu.

O novo quadro envolvia não somente os novos territórios, mas também a justificação dos direitos a essas novas terras e de conquista dos povos que ali se encontravam. ${ }^{4}$ É igualmente digno de nota que o projeto de catequização desenvolvido pela Igreja Católica acompanha esse movimento, uma vez que a Igreja também procurou ampliar a sua influência em direção às novas terras. ${ }^{5}$ Todavia, o projeto colonialista da Igreja Católica dependia amplamente daquele das monarquias, uma vez que a Igreja

\footnotetext{
2 Este artigo foi apresentado no evento "Die Rezeption der aristotelischen politischen Philosophie in der frühneuzeitlichen lateinamerikanischen Scholastik", organizado por Roberto Hofmeister Pich, na Universidade de Bonn, Alemanha, em 21/02/2019. Agradeço ao professor Roberto Pich e aos demais integrantes do evento pela discussão que seguiu a apresentação do texto e que permitiu o seu aprimoramento.

3 Cunha, M. S. "A Europa que atravessa o Atlântico (1500-1625)". In: Fragoso, J. e Gouvêa, M. F. O Brasil Colonial, 1443-1580. Rio de Janeiro: Civilização Brasileira, v. 1, p. 271-314.

4 A bibliografia sobre esse tema é imensa. A título de exemplo citemos apenas: Vicente Pereña, L. Mission de España en America 1540-1560. Madrid: Consejo Superior de Investigaciones Cientificas, 1956 e Vicente Pereña, L. Carta Magna de los Indios. Salamanca: Universidad Pontificia de Salamanca, 1996.

5 Para uma caracterização do fenômeno, veja-se Boxer, C. R. A Igreja militante e a expansão ibérica: 1440-1770. Tradução Vera Maria Pereira. São Paulo: Companhia das Letras, 2007.
} 
necessitava das coroas não somente para alcançar os novos territórios, mas também para mantê-los uma vez que a Igreja estivesse instalada. Essa dependência é particularmente clara no caso da colonização do Brasil, já que a implantação dos jesuítas foi, em grande medida, economicamente dependente dos subsídios financeiros aportados pela coroa portuguesa. ${ }^{6}$

Ambos os projetos, o das monarquias e o da Igreja Católica, foram projetos colonizadores com pretensões globais que, ainda que interdependentes, mantiveram certas tensões entre si. A Igreja Católica, segundo a própria natureza do projeto de catequização, necessitava introduzir considerações sobre as novas populações que as apresentassem de uma maneira que fosse de certo modo universal.7 Em outras palavras, para o propósito do projeto de catequização, se o outro a ser catequizado não pudesse ser pensado como um igual, se o outro fosse apenas aquele que, em virtude de sua natureza, pudesse ser submetido exclusivamente pela força, então não haveria catequização possível. Mesmo admitindo, como fizeram os jesuítas instalados no Brasil, a necessidade de submeter as populações indígenas como condição para sua catequização, ${ }^{8}$ era fundamental, à luz do projeto de catequização, sustentar que os povos indígenas deveriam ser considerados naturalmente iguais, pois o reconhecimento de sua igualdade natural era condição necessária para que se tornassem membros da comunidade cristã. Como os jesuítas instalados no Brasil afirmariam explicitamente, o

\footnotetext{
6 Sobre o papel dos jesuítas no Brasil, veja-se os estudos seminais de Castelnau-l'Estoile, C. Operáios de uma vinha estéril. Os jesuitas e a conversão dos índios no Brasil - 15580-1620. Tradução de llka Stern Cohen. São Paulo: Edusc, 2006.

7 Alguns autores preferem caracterizar a posição da Igreja frente às novas populações a partir do que chamam de imperativos evangélicos. Sobre isso, veja-se Hornaert, E. et alii. História da Igreja no Brasil. Ensaio de interpretação a partir do povo. Primeira época - período colonial. Petrópolis: Vozes, 5. ed., 2008, p. 143.

8 Sobre isso, consulte-se a análises sempre precisas de: Zeron, C. A. M. R. Linha de fé. A Companhia de Jesus e a escravidão no processo de formação da sociedade colonial (Brasil, séculos XVI e XVII). Tradução de Antônio de Padua Danesi. São Paulo: Edusp, 2011. O tema não é estranho a Alonso de la Vera Cruz. Sobre isso, veja-se: Heredia, R. Coacción para la fe. Una aproximación al tratado De dominium infidelium et iusto bello de fray Alonso de la Vera Cruz. Tópicos, 34, p. 157-208, 2008.
} 
objetivo era tornar aquela terra uma parte católica do império português, e isso que significava assimilar o indígena ao modo de ser cristão.

Em suma, de um lado, havia a perspectiva do conquistador, representada, no caso do Brasil, pelos colonos portugueses. Essa era a da guerra de conquista, a que via no outro, no indígena, aquele a ser conquistado, reduzindo assim os nativos americanos à mão de obra para o projeto colonial conquistador. De outro lado, havia a perspectiva da Igreja Católica. Essa precisava admitir, na pessoa do outro, uma certa natureza compartilhada. Algo que possibilitasse reconhecer essas pessoas como livres e iguais, senão pelas condições de desenvolvimento, pelo menos por sua condição natural. ${ }^{9}$ Obviamente, não será a nossa intenção aqui adentrar nos inúmeros debates que surgiram dessa tensão. Para nossos propósitos, basta notar que as duas perspectivas apontadas podem ser identificadas no Brasil colonial e se manifestam nas disputas quase constantes entre os colonos portugueses e os missionários jesuítas. ${ }^{10}$ Como veremos mais adiante, o mesmo pode ser dito no caso da Nova Espanha, embora de uma forma ligeiramente diferente.

Note-se, no entanto, que as disputas entre as monarquias europeias e a Igreja Católica não surgiram apenas em razão da conquista dos territórios descobertos no início do século XVI. Na verdade, elas ocorriam também internamente à Europa e tinham raízes mais antigas, podendo ser encontradas no funcionamento das instituições jurídicas. Para esse caso podemos, mais uma vez de uma forma muito simplificada, identificar dois períodos. O primeiro corresponde à centralização legislativa por parte do poder real. Esse é o período mais próximo do final da Idade Média em que

\footnotetext{
9 Veja-se, por exemplo, Calafate, P. “Estudo Introdutório I - A guerra justa igualdade natural dos povos: os debates ético-jurídicos sobre os direitos da pessoa humana". In: Calafate, P. (org.). A Escola Ibérica da Paz nas Universidades de Coimbra e Évora (século XVI). Coimbra: Almedina, 2 vols, 2015, p. 17-47.

10 Veja-se, por exemplo, a Apologia pro Paulistis (1684), transcrição C. A. M. R. Zeron, tradução R. Ruiz. Clio - Série Revista de Pesquisa Histórica, n. 26-2 (2008), p. 363-416 e a análise de Zeron, C. A. R. M., "Interpretações de Francisco Suárez na Apologia pro paulistis (1684)". In: Mezan Algranti, L. M. e Torres Megiani, A. P. (org.). O Império por escrito. Formas de transmissão da cultura letrada no mundo ibérico (séc. XVI-XIX). São Paulo: Alameda, 2009.
} 
as cortes reais, inicialmente atuando de forma pontual na administração da justiça, baseiam as suas ações em uma forma de direito que havia sido desenvolvida nas universidades, o ius commune." Progressivamente, esse modelo de tomada de decisão através da administração da justiça começou a dar lugar a um modelo de criação legislativa através de decretos, 0 que levou, no século XVI, à tentativa de submeter até mesmo as cortes eclesiásticas ao poder legislativo e decisório das cortes reais.

O segundo período é o da reação da Igreja às novas doutrinas acerca da legislação. Uma tentativa foi feita para remover a atividade legislativa das cortes reais ${ }^{12}$, criando novos fóruns, com especial preeminência sobre as noções de lei natural, forum internum e ênfase nos direitos naturais que limitavam o poder legislativo dos monarcas. O ponto central a destacar aqui é a criação do forum internum como um domínio de consciência ou pecado. Esse fórum foi associado à relação com Deus e ao sacramento da penitência. O forum externum, por sua vez, dizia respeito a faltas cometidas contra a sociedade e perseguidas pela jurisdição eclesiástica ou civil. Como todo católico estaria sujeito à jurisdição do forum internum, até mesmo a consciência do rei poderia ser julgada pelo confessor e o rei poderia, portanto, ser absolvido, ou não, por ter praticado certos atos. ${ }^{13}$

O que nos interessa nesse movimento é a emergência de uma tese, defendida por vários juristas da época, a saber, a da limitação do poder

\footnotetext{
1 Veja-se Cairns, J. W. e du Plessis, P. J. (ed.). The Creation of the lus Commune. From Casus to Regulae. Edinburgh: Edinburgh University Press, 2012.

12 A historiografia portuguesa tem abordado a questão chamando a atenção para a origem democrática do poder civil. Veja-se: Merêa, P. Sobre a origem do poder civil. Estudos sobre o pensamento político e jurídico dos séculos XVI e XVII, introdução e seleção M. N. de Brito. Coimbra: Edições Tenacitas, 2003.

13 Goering, J. "The Internal Forum and the Literature of Penance and Confession". In: Hartmann, W. and Pennington, K. (ed.). The History of Medieval Canon Law in the Classical Period, 11401234: From Gratian to the Decretals of Pope Gregory IX. Washington: Catholic University of America Press, 2008, p. 379-428; Prodi, P. Una historia de la justicia. De la pluralidad de fueros al dualismo moderno entre conciencia y derecho, traducido por L. P. López. Buenos Aires: Katz Editores, 2008; Decock, W. "Rumo a uma ciência do direito jesuítica". Revista do Instituto Histórico Geográfico do Rio Grande do Sul, n. 151, p. 73-110, 2016.
} 
legislativo dos monarcas por meio de direitos. Podemos resumir o ponto invocando um importante historiador do Direito romano e moderno:

Ao longo do século XVII, os direitos civis, o patrimônio mais importante do Direito Romano, foram cada vez mais considerados como direitos privados do indivíduo que transcendem as jurisdições nacionais. Para conhecer o seu conteúdo, procurou-se o Corpus iuris. Esta visão europeia do direito privado promoveu o comércio, a cooperação entre fronteiras e contribuiu para a recuperação da riqueza. $O$ renascimento do Corpus iuris e do direito romano na era moderna foi, portanto, a-histórico. As pessoas não procuravam a velha doutrina jurídica, mas sim um novo pensamento jurídico. Com o Corpus iuris, buscava-se salvaguardar os direitos privados dos cidadãos. ${ }^{14}$

De fato, durante o século XVI, uma característica importante dos pensadores que atuavam na Igreja Católica era o fato de que muitas vezes eles possuíam uma formação dupla: teológica e jurídica, a tal ponto que um tipo particular de literatura aparece no período, a saber, obras intituladas De iustitia et iure. Esse verdadeiro gênero literário tomou a forma de comentários sobre a Suma de Teologia de Tomás de Aquino e resultou em novas peças de criação e debates legislativos, já que a autoridade dos teólogos finalmente forneceu os parâmetros de julgamento a serem empregados para avaliar a consciência moral. Como eram juristas formados muitas vezes em direito civil e eclesiástico, voltaram-se para o Corpus Iuris Ciuilis para encontrar formulações de Direito dotadas de autoridade que só uma tal fonte poderia conferir. No entanto, essa fonte foi reinterpretada segundo um modelo de pessoa moral característico do cristianismo. Assim, o Corpus luris começou a ser lido como um verdadeiro depositário de direitos universais que promovia a liberdade e a

14 Waelkens, L. Amne Adverso: Roman Legal Heritage in European Culture. Leuven: Leuven University Press, 2015. 
igualdade natural de todos os seres humanos. Não é de surpreender que boa parte desses teóricos apoiasse enfaticamente uma tese muito próxima daquela que encontramos, por exemplo, no preâmbulo da Declaração de Independência dos Estados Unidos, ou seja, que todos os homens nascem naturalmente livres e iguais, porque foram criados por Deus.

Um segundo aspecto a realçar na citação de Walkens diz respeito à noção de interpretação a-histórica do Direito. Sustentar que esses juristas empregaram um método a-histórico de interpretação do Corpus luris não é o mesmo que dizer que estavam certos ao fazerem isso. Não é correto, portanto, ler essa afirmação sem considerar também as críticas vindas das escolas históricas do Direito sobre o método empregado por esses teólogos-juristas. Todavia, para os nossos objetivos basta apontar para a função retórica que essa estratégia interpretativa desempenhou à época. Por ser uma compilação legal investida de autoridade histórica milenar e por transmitir certos ideais de igualdade e liberdade que permitiam interpretações universais, o Corpus luris ofereceu terreno fértil para autores que procuravam defender uma teoria sobre direitos individuais que oferecia limites aos poderes dos monarcas. Se quisermos, no entanto, procurar as verdadeiras raízes dessas teorias, não as encontraremos no próprio Corpus luris, mas na tradição do Direito canônico. De fato, um aspecto que tem sido muito enfatizado nas últimas décadas é precisamente a importância que o Corpus luris Canonici (ou Corpo de Leis Canônicas) teve para o desenvolvimento do Direito ocidental medieval e moderno. ${ }^{15}$

\section{Alonso de la Vera Cruz: por que o casamento era um problema}

Alonso de la Vera Cruz ocupa certamente uma posição de destaque na história do pensamento colonial. De nome de batismo Alonso Gutiérrez

\footnotetext{
15 Veja-se: Gordley, J. The Philosophical Origins of Modern Contract Doctrine. Oxford: Clarendon Press, 1993; Decock, W. Theologians and Contract Law. The Moral Transformation of the Ius Commune (ca. 1500-1650). Leiden: Martinus Nijhoff Publishers, 2013.
} 
(c.1507-1584 $)^{16}$, estudou gramática e lógica na Universidade de Alcalá e formou-se em Teologia pela Universidade de Salamanca, onde foi aluno de Francisco de Vitória e Domingo de Soto. Ordenado sacerdote secular, iniciou a sua carreira docente na Universidade de Salamanca (15321535). Uma brilhante carreira era-lhe prometida quando foi recrutado por Francisco de la Cruz, missionário agostiniano no novo mundo que procurava um mestre em Teologia capaz de ensinar os novos membros da ordem agostiniana. Em 1536, Alonso Gutiérrez mudou-se para a Nova Espanha e ingressou na ordem agostiniana com o nome de Alonso de la Vera Cruz, em homenagem à cidade onde havia chegado.

Alonso esteve envolvido na criação de várias novas universidades e bibliotecas: Tiripetío (1540), onde fundou a primeira biblioteca do Novo Mundo, Tacámbaro (1545) e Atotonilco (1546). Foi ainda um dos primeiros professores da recém fundada Universidade do México (1553), onde ensinou teologia e publicou o que é considerado o primeiro cursus philosophicus do Novo Mundo. As duas primeiras partes do curso (Recognitio Summularum e Dialectica Resolutio) são dedicadas à lógica e foram publicadas em 1554. A terceira parte, Physica speculatio, cobre os livros aristotélicos sobre a Física, como o De caelo, De meteoris, De generatione et corruptione e o De anima, tendo sido publicado três anos depois, em 1557. O cursus de Alonso foi amplamente reconhecido dentro e fora da ordem e, em 1569, o Capítulo Provincial recomendou seu uso por todos os professores da ordem agostiniana.

Escrever um comentário aos trabalhos políticos ou éticos de Aristóteles não estava entre as obrigações primeiras de Alonso como um professor. Consequentemente, a fim de compreendermos o modo como ele se apropriou desta parte do corpus aristotélico, devemos mudar nossa

\footnotetext{
16 Beuchot, M. "Perfil del pensamiento filosófico de fray Alonso de la Vera Cruz". Nova Tellus, 29 (2011), p. 201-214; Sevilla, F. C. F. "Analisis socio-bibliográfico de fray Alonso de Veracruz, OSA (Caspueñas - Guadalajara, España - 1507 / México, Nueva España, 1584)". Anuario Jurídico y Económico Escurialense, 41 (2008), p. 831-850; Diaz, G. D. Hombres y documentos de la filosofia española. Madrid: Consejo Superior de Investigaciones Científicas, v. 1, 1998, p. 198-202; consulte-se também o estudo de Roberto Heredia Correa em: de la Vera Cruz, A. Sobre el Dominio de los indios y la Guerra Justa, edición, introducción y notas R. H. Correa. Ciudad Universitaria: UNAM, 2004.
} 
atenção para dois trabalhos de natureza distinta da de um comentário. Primeiramente para o De Dominium Infidelium, que é uma Relectio lida por Alonso enquanto professor de Teologia e publicada apenas em 1968 por Ernest Burrus. ${ }^{17}$ De modo mais central, devemos, no entanto, consultar o seu Speculum Coniugiorum o qual fornece uma análise teológica e jurídica acerca da noção de casamento no Novo Mundo. Esta segunda obra foi publicada pela primeira vez no México em 1556 e, em 1571, incorporou um anexo para estar de acordo com as novas resoluções sobre o matrimônio promulgadas, em 1563, pelo Concílio de Trento. O Speculum Coniugiorum mostra-se assim uma obra bastante singular. Por um lado, procura abordar alguns problemas concretos encontrados pelos missionários no Novo Mundo e oferecer-lhes uma solução baseada em princípios éticos e políticos aristotélicos. Por outro, as soluções que propõe não foram diretamente afetadas pelas novas resoluções do Concílio, como é comprovado pelo fato de que um simples apêndice, e não uma reelaboração completa de todo o livro, foi suficiente para atualizar o trabalho às novas exigências do Concílio.

Se perguntarmos agora por que Alonso de la Vera Cruz decidiu escrever sobre esse tema, a resposta é precisamente a importância da noção de casamento para o projeto catequizador. ${ }^{18}$ Não bastava um esforço missionário para levar as populações indígenas a acreditarem no Deus cristão. O objetivo da conversão era fazer com que elas ingressassem e vivessem em uma comunidade católica, o que significava dizer que os neófitos deveriam abraçar um novo modo de vida e viver as suas vidas de uma nova maneira política. Uma comunidade católica é, em geral, uma forma de vida política com regras e práticas que exigem serem seguidas diariamente. Como é particularmente claro nas disputas entre protestan-

\footnotetext{
17 Burrus, E. J. The Writtings of Alonzo de la Vera Cruz. The Original Texts with English Translation. 5 v., St, Louis: Jesuit Historical Institute, 1968-1976.

18 Consulte-se também: Ordeñana, J. G. "El 'speculum coniugiorum' de Alonso de la Veracruz y la inculturación del matriminio canónico en México". Ius canonicum, 39 (1999), p. 619-32 e Assimakópulos, A y Contreras, S. "Matrimonio y derecho natural e Alonso de Veracruz (15071584). Revista de Estudos Históricos-Jurídicos, 39 (2017), p. 173-193.
} 
tes e católicos durante o século XVI, o que especificava uma comunidade católica e tornava-a diferente das demais comunidades cristãs era o modo como ela entendia os sacramentos. Perguntas como quantos sacramentos existem, como são definidos, quem poderia administrá-los e como, quais são os efeitos dos sacramentos, ou quais são aqueles necessários para a salvação, não eram perguntas anódinas, especialmente para os missionários no Novo Mundo, cuja tarefa não era somente assegurar a conversão de uma população recém-descoberta, mas mantê-la católica. Aos olhos dos missionários, se o batismo era o primeiro sacramento a ser administrado e representava a entrada principal na comunidade católica, o matrimônio, considerado como um sacramento, possuía o poder de conferir estabilidade à comunidade católica, pois era destinado a criar uma forma indissolúvel de sociedade. Seguindo Aristóteles, Alonso a denomina como a primeira forma de sociedade, aquela entre um homem e uma mulher cuja prole seria capaz de assegurar a continuidade de toda a comunidade.

Se não é difícil compreender o papel que o matrimônio desempenhava no projeto de conversão, é igualmente importante notar que o matrimônio católico comportava igualmente exigências que podiam parecer demasiadamente rígidas aos olhos da população indígena. Com efeito, a existência no Novo Mundo de diversas formas de relações humanas com estruturas sociais mais flexíveis teria de ser abandonada para permitir a introdução de uma família monogâmica e dotada da união indissolúvel do casal. Isso, naturalmente, deu origem a diversos problemas. Por um lado, uma queixa comum dos missionários era o fato de que quando um casal indígena solicitava a um sacerdote que lhes casasse, o missionário precisava, primeiramente, perguntar se eles já tinham tido maridos ou esposas. Dado que esse era muitas vezes o caso, o matrimônio estava impossibilitado e o risco de perder o casal recém-convertido não era desprezível. Por outro lado, um argumento frequentemente utilizado pelos colonos para sustentar que a população indígena era incapaz de se tornar cristã, e que deveria ser reduzida à escravidão, era precisamente o fato de que os indígenas praticavam a poligamia. 
Em outras palavras, a pergunta "Os povos indígenas são capazes de se casar?" representava um verdadeiro dilema para o projeto missionário. Uma resposta negativa implicaria, evidentemente, a impossibilidade da conversão, pois levaria à impossibilidade de criar e manter uma comunidade de indígenas cristãos. Uma resposta afirmativa era, portanto, necessária, mas pressupunha que era possível não só sustentar que a forma católica do matrimônio era a correta, mas também provar que, apesar de suas práticas, os povos indígenas reconheciam uma certa forma de matrimônio e, portanto, poderiam abraçar a sua forma católica. Como veremos em um momento, a maneira que Alonso encontrou para resolver esses problemas foi explorar a noção aristotélica de casamento como uma união natural entre um homem e uma mulher. Passemos, então, a apresentar brevemente as características mais salientes de sua solução.

\section{De la Vera Cruz e o Speculum Coniugiorum}

Alonso de la Vera Cruz divide o seu Speculum Coniugiorum ${ }^{19}$ em três partes. A primeira é dedicada ao tratamento do casamento de maneira geral e de seus impedimentos, a segunda trata especificamente do casamento dos infiéis, enquanto a terceira trata do divórcio. As edições posteriores ao Concílio de Trento incorporam, como já dissemos, um anexo onde se analisam algumas dúvidas que poderiam surgir acerca das novas determinações do Concílio. Incluem também as decisões papais que conferem privilégios aos missionários do Novo Mundo. Não nos interessará aqui analisar os diversos aspectos que o problema recebe sob

\footnotetext{
19 de la Vera Cruz, A. Speculum conjugiorum, Mediolanum, 1599. Usaremos como referência a tradução espanhola de Fontana, L. B. El Speculum Coniugiorum"de fray Alonso de la Vera Cruz. Traducción y comentarios, tesis que apresenta para obtener el grado de Maestro en Letras Clásicas. Universidad Nacional Autónoma de Mexico, 2006. Doravante, citaremos como SC, seguido do número da página.
} 
a pena de Alonso de sorte que nossa intenção estará limitada ao modo como ele se apropria da Política de Aristóteles. ${ }^{20}$

Alonso começa seu tratamento do casamento através da famosa distinção aristotélica entre an est e quid est e sustenta que, como havia dito o Filósofo, não é possível responder à pergunta pela essência de algo sem previamente provar a sua existência. ${ }^{21} \mathrm{~A}$ forma como essas duas perguntas são respondidas é bastante interessante. Ao tratar da primeira questão (an est), o autor mobiliza teses e argumentos estritamente teológicos, já que o casamento é considerado uma instituição divina. A resposta à pergunta sobre a sua essência (quid est), por sua vez, depende em grande medida da noção aristotélica da natureza e do que significa para os seres humanos possuírem comportamentos naturais.

Ao responder à pergunta an est, Alonso distingue três momentos. Primeiramente, o casamento foi instituído antes do pecado (ante peccatum) e com uma função específica (officium). Como declarado no livro da Gênesis, Deus criou a mulher com o propósito de prover Adão com alguém semelhante a ele que pudesse ajudá-lo. O próximo passo foi estabelecer o momento exato em que o casamento foi instituído e como foi realizado, pois esse era um assunto muito discutido na tradição. Para Alonso, o casamento foi instituído por um ato de Deus quando Adão adormeceu e Deus formou Eva de sua costela. No entanto, como o casamento requer consentimento, o casamento só ocorreu quando Adão expressou a sua

\footnotetext{
20 Para uma visão geral da obra, consulte-se as seguintes teses de doutoramento: Campos, Y. E. M. La ley natural y el matrimonio en el Espejo de los cónyuges de Alonso de la Vera Cruz. La problemática sobre la ley natural y la diversidad cultural en los albores de la nation mexicana. Tesis que para obtener el título de Doctora en Filosofia. México: Universidad Panamericana, 2010; Fontana, L. A. B. Matrimonio, familia y divorcio. Actualidad de los principios del derecho matrimonial y familiar según el Speculum Coniugiorum de Fray Alonso de la Vera Cruz. Tesis para optar por el grado de Doctor em Letras. Universidad Nacional Autónoma de Mexico: 2010. Esta tese contém a tradução da segunda e terceira partes do Speculum Coniugiorum. Veja-se ainda: Ponce, C. La liberdad en el Speculum de Alonso de la Vera Cruz. In: Gómez, A. V. (org). Fray Alonso de la Vera Cruz: universitário, humanista, cientifico y republicano. Ciudad Universitaria: Universidad Nacional Autonoma de México, 2009, p. 155-171.

${ }_{21}$ «Quia (teste Aristotele) an est, prius est, quam quid est, frustra, et inassum in quaestione ponetur quid sit matrimonium, nisi prius intellexerimus an sit.» SC, 1.
} 
vontade por meio das seguintes palavras: "Esta finalmente é osso dos meus ossos e carne da minha carne."22 Somente após, Deus teria afirmado a inseparabilidade, a fidelidade e o bem da descendência. O segundo momento ocorrera após o pecado (post peccatum), quando o casamento foi estabelecido e confirmado como um remédio para que o vício da carne fosse contido e para que o casamento fosse realizado sem pecado. O terceiro e último momento teria ocorrido sob a lei da graça, quando o casamento foi confirmado por Cristo na forma de indissolubilidade. ${ }^{23}$

Se compararmos a interpretação de Alonso de la Vera Cruz com o parágrafo introdutório à doutrina do casamento promulgada pelo Concílio de Trento, veremos que é basicamente a mesma, diferindo em alguns detalhes e, obviamente, na introdução do vocabulário aristotélico por Alonso. Vejamos o texto do Concílio:

O primeiro pai da raça humana, sob a influência do Espírito divino, pronunciou o vínculo do matrimônio perpétuo e indissolúvel, quando disse: Esta agora é osso dos meus ossos e carne da minha carne. Portanto o homem deixará pai e mãe, unir-se-á à sua mulher e serão dois na mesma carne. Mas que por este vínculo somente dois estão unidos e unidos, nosso Senhor ensinou mais claramente, ao ensaiar estas últimas palavras como tendo sido pronunciadas por Deus. Ele disse, portanto agora não são duas, mas uma só carne; $\mathrm{e}$ logo confirmou a firmeza daquele laço, proclamado há tanto tempo por Adão, por estas palavras: O que, portanto, Deus

22 Gen. 2, 23: "dixique Adam hunc nunc os ex ossibus meis et caro de carne mea". In Biblia Sacra Vulgata. Stuttgart: Deutsche Bibelgesellschaft, 2005.

${ }_{23}$ Convém lembrar aqui que, para Agostinho de Hipona, os três bens (bona) do casamento são os filhos (proles), a fidelidade dos cônjuges (fides) e o sacramento que garante a estabilidade da união. Os dois primeiros bens seriam de direito natural e conhecidos por todos os povos ao passo que o sacramento seria distintivo da união cristã. Sobre o papel desempenhado por Agostinho na formação da noção católica de casamento, veja-se: Witte Jr, J. From Sacrament to Contract. Marriage, Religion, and Law in the Western Tradition. Louisville: Westminster John Knox Press, 2. ed., 2012, p. 65-75. 
uniu, que nenhum homem separe. Mas a graça que poderia aperfeiçoar esse amor natural, confirmar essa união indissolúvel e santificar os casados, o próprio Cristo, o instituidor e aperfeiçoador dos veneráveis sacramentos, mereceu para nós pela Sua paixão, como o Apóstolo Paulo intimida, dizendo: maridos amem vossas esposas, como também Cristo amou a Igreja e se entregou por ela; acrescentando pouco depois: Este é um grande sacramento, mas eu falo em Cristo e na Igreja. ${ }^{24}$

Um breve comentário acerca desse texto. O Concílio descreve a criação do casamento em dois passos, antes do pecado e depois da graça, enquanto Alonso apresenta-nos três. Esta pequena diferença pode ser explicada pelo modo como o próprio autor apresenta a sua intenção com o Speculum Coniugiorum. Afirma Alonso:

Não pretendo editar coisas novas, mas sim sintetizar e esclarecer, se necessário, as que recebemos dos nossos mestres mais eloquentes ou silenciosos e explicá-las e expandi-las quando o caso o exigir. Isso não acontecerá ou vez ou outra, mas frequentemente (SC, L. 2, p. 1).

Assim, o fato de Alonso ter usado três momentos para descrever a criação do casamento é talvez um dos casos que, aos seus olhos, requeira simplesmente uma explicação mais detalhada, sem ser necessário ver aí uma inovação doutrinária. Note-se, porém, que ao descrever a instituição do casamento por Deus, Alonso acrescenta algo que não encontraremos nos ditames do Concílio, a saber, que, quando Adão recebeu uma ajuda semelhante a si na pessoa de Eva, o casamento foi introduzido com uma

24 As disposições do Concílio Tridentino podem ser encontradas disponíveis no link: http:// www.documentacatholicaomnia.eu/o3d/1545-1545,_Concilium_Tridentinum,_Canons_And_ Decrees,_EN.pdf. Acesso em: 1 jul. 2019. 
função (in officium). ${ }^{25}$ Inicialmente, Alonso não explica por que Adão precisaria de ajuda, nem qual seria a função que seria exercida. Esses pontos, deixados inexplorados na resposta teológica à pergunta an est, permitirão, ao responder à pergunta quid est, um tratamento da noção de casamento como um fenômeno natural. O casamento será visto como algo que desempenha uma função natural na vida humana e que pode ser compreendido em termos da filosofia natural e política de Aristóteles. ${ }^{26}$

Não é surpreendente, portanto, que Alonso entenda a pergunta pela essência do casamento como equivalente à questão de saber se o casamento é natural. Como o casamento foi instituído antes do pecado, então, mesmo que o pecado original jamais tivesse ocorrido, ainda assim haveria a figura do casamento. Resta, portanto, por explicar por que Deus decidiu instituí-lo, o que equivale a perguntar pela função específica que o casamento deve desempenhar. Ora, essa função somente pode ser entendida como a realização de um propósito natural e esse seria a multiplicação da raça humana e a preservação da espécie. Além disso, se o matrimônio é natural e dado que as realidades naturais não foram abolidas pelo pecado original, mas ficaram apenas feridas (sauciata), então não se pode negar que haja também matrimônio entre os pecadores. Além disso, como entre os infiéis as coisas naturais são mantidas intactas, mesmo que obscurecidas, deve-se afirmar que mesmo entre os infiéis há matrimônio. ${ }^{27}$

Como dito, Alonso baseia o seu tratamento da essência do casamento reivindicando explicitamente a autoridade de Aristóteles, pois encontrará

\footnotetext{
25 "[...] matrimonium a Deo ipso omnium formatore esse institutum affirmamus: in officium quidem, in illo deliciarum paradiso ante peccatum protoplastorum." SC, 1. Compare-se com Tomás de Aquino, Suma de Teologia, Supl., q, 59, a. 2, passagem na qual o autor trata do casamento dos infiéis e sustenta ter sido o matrimônio instituído "in officium naturae". Esse ponto será decisivo para Alonso.

${ }^{26}$ Sobre a noção de lei natural em Alonso, consulte-se ainda: Medina, V. "Lei natural y matrimonio en el Speculum de Alonso de la Vera Cruz". In: Gómez, A. V. (org). Fray Alonso de la Vera Cruz: universitário, humanista, científico y republicano. Ciudad Universtiaria: Universidad Nacional Autonoma de México, 2009, p. 125-142.

27 "Quia cum infidelis naturalia integra retineant, licet obtenebrata, omnino et constanter affirmare necesses erit, apud infideles etiam matrimonium esse." SC, 1.
} 
no Filósofo o princípio explicativo geral do funcionamento da natureza. Baseado no Livro 2 da Física, Alonso sustenta que, nas coisas naturais, a necessidade deve ser considerada do ponto de vista da finalidade. Assim, se a natureza dotou o ser humano de olhos e se a função dos olhos é ver, então é natural que eles tenham sido colocados na cabeça e não nos pés. ${ }^{28}$ Em seguida, Alonso reivindica uma famosa passagem da Ética Nicomaqueia na qual Aristóteles afirma estar o ser humano por natureza mais inclinado à vida conjugal do que à política. ${ }^{29}$ Trata-se de uma passagem tradicionalmente citada e que já havia sido empregada por Tomás de Aquino em seu Comentário às Sentenças de Pedro Lombardo e que foi publicada como Suplemento à Terceira Parte da Suma de Teologia..$^{30}$ Tomás, entretanto, cita a passagem em um sed contra, sem a explorar. Para Alonso, essa passagem torna-se a base do argumento. O ser humano é, por natureza, mais conjugal que político porque a união conjugal é a formação de uma sociedade natural (societas naturalis) necessária para que a natureza se perpetue..$^{31}$ Os seres humanos reúnem-se politicamente porque não são capazes de obter autonomamente todas as coisas de que precisam para viver, necessitando de ajuda da comunidade para tanto. Outros animais, por outro lado, foram naturalmente dotados dos meios pelos quais podem alcançar a sua sobrevivência, mas o ser humano tem apenas a razão e ninguém é capaz de conhecer sozinho todas as coisas de que necessita. Uma

\footnotetext{
28 "Pro dubii solutione notanda est Aristotelis doctrina dicentis, quod necessitas in naturalibus sumenda ex fine est: ac si diceret. Dedit homini natura, oculos ad videndum, ad tuendum se, et ad cauendum a periculis imminentibus: necesse est ergo, quod oculi sint positi in capite et non in pedibus: quia non posset homo commode finem praeoptatum consequi, si in pedibus essent." SC, 2

29 «Matrimonium coniunctio scilicet maris, et foeminae, est de iure naturae. Probatur ex Aristotele. Homo est naturaliter magis animal coniugale, quam politicum." SC, 2. A passagem corresponde ao texto de Aristóteles em 1162a15-17.

30 «Philosophus, VIII Ethic., dicit quod homo est magis naturaliter coniugale animal quam politicum. Sed homo est naturaliter animal politicum et gregale, ut ipse dicit. Ergo est naturaliter coniugale. Et sic coniugium, sive matrimonium, est naturale.» Summa Theologiae, Supl., q. 41, a. 1, p. 78.

${ }_{31}$ Sobre esse texto de Aristóteles, veja-se: ASPE, V. Las consequencias del Homo est naturaliter magis animal coniugale quam politicum en el Speculum de Alonso de la Vera Cruz. In: Gómez, A. V. (org.). Fray Alonso de la Vera Cruz: universitário, humanista, científico y republicano. Ciudad Universtiaria: Universidad Nacional Autonoma de México, 2009, p. 143-153.
} 
inclinação natural fez-se, portanto, necessária para que os seres humanos se unam para ajudarem-se mutualmente. Notemos novamente aqui o apelo à noção de ajuda mútua, que não é mais interpretada em termos teológicos, como no caso da criação de Eva, mas em termos aristotélicos. Os seres humanos constituem naturalmente comunidades políticas porque dependem de assistência mútua. Conclui-se, assim que, se o ser humano é naturalmente um animal político ou social e é mais matrimonial, a união conjugal é natural e a natureza inclina-se para ela. Por essa razão, diria o Filósofo, a primeira sociedade (prima societas) é a união de marido e muIher, como se Aristóteles estivesse afirmando que a sociedade política ou econômica depende dela. Em outras palavras, se a natureza inclina para a sociedade política, a fortiori inclina para o casamento. Não é por outra razão que o Digesto afirma que a conjunção entre marido e mulher, chamada casamento, é um dispositivo do Direito Natural. E esse é o segundo sed contra citado por Tomás de Aquino no primeiro artigo da pergunta 41.

Em seguida, Alonso afirma que, para se ter uma perfeita compreensão da tese acima, deve-se prestar atenção à polissemia da palavra "natural". Sua explicação baseia-se novamente na solução do primeiro artigo da questão 41 de Tomás de Aquino, ainda que as referências fornecidas nas notas laterais do texto, mesmo citando Tomás, nunca se refiram a essa questão. Em um primeiro sentido, é natural aquilo que necessariamente resulta dos princípios da natureza, pois é natural que a pedra caia e que o fogo suba. Obviamente, o casamento não é natural nesse sentido, uma vez que não é causado pela necessidade (ex necessitate), mas pela vontade (ex voluntate) através do livre consentimento. ${ }^{32}$

Em um segundo sentido, é natural aquilo a que a natureza se inclina, mas que recebe o complemento da parte do livre arbítrio. O mesmo acontece com as virtudes que estão naturalmente no ser humano, mas não

\footnotetext{
32 Pro perfecta intelligentia est notandum, quod naturale dicitur dupliciter. Vno modo, quod causam habet ex princiis naturae ex necessitate, sicut necessarium est lapidem descendere, propter suam grauitatem, et ignem ascendere, propter suam levitatem. Et isto modo matrimonium non est naturale: quia non ex necessitate causatur, sed ex voluntate per liberum consensum." SC, 2.
} 
porque sejam completas e perfeitamente geradas no ser humano, mas porque podem ser adquiridas através da ação. ${ }^{33}$ Neste segundo sentido, o matrimônio é natural ou de direito natural na medida em que os seres humanos estão inclinados a ele por natureza, ainda que dependa do consentimento do livre arbítrio para a sua realização. Em outras palavras, ainda que os seres humanos busquem o matrimônio por livre arbítrio, essa união é natural porque o buscam por uma inclinação natural, ainda que essa inclinação seja complementada pela vontade. ${ }^{34}$

Ainda seguindo a estrutura argumentativa proposta por Tomás de Aquino, Alonso continua a abordar o duplo propósito do casamento, mesmo que, diferentemente de Tomás, os dois propósitos não sejam hierarquicamente estruturados. O primeiro propósito seria a propagação e a continuidade da espécie, que ele chama de bem comum (bonum commune), enquanto o segundo seria a ajuda mútua e a comunidade de tarefas. ${ }^{35}$

Apelando mais uma vez ao princípio teleológico aristotélico segundo o qual a natureza toma a necessidade da finalidade, Alonso de la Vera Cruz associa a cada um dos fins certas características do casamento. No caso da continuidade da espécie, essa implica a necessidade de relações sexuais, embora não se limite ao puro ato. Ao contrário do que acontece com certos tipos de animais, o matrimônio humano deve obedecer a certas condições. Em primeiro lugar, a necessidade de pessoas de sexos diferentes. Em segundo, que o ato seja realizado com uma só mulher; terceiro, que haja certas pessoas que são excluídas da conexão, os pais, por exemplo; quarto, que a relação deva ser duradoura, pois o que se busca não é só

\footnotetext{
33 "Secundo modo id dicitur esse naturale, ad quod natura inclinat, tamen complementum accipit a libero arbitrio: sicut dicuntur virtutes naturaliter inesse homini, non quod inueniantur in nobis aliqui habitus perfecti per naturam, sed inest nobis a natura suscipere illas per operationes nostras, sicut Aristoteles docet." SC, 2.

${ }_{34}$ "Sic in proposito, licet homo per liberum arbitrium ad matrimonium moueatur, naturale quidem est quia ad allud est inclinatio naturalis, licet compleatur per voluntatem". SC, 2.

35 "Praeterea notandum est, duplicem esse finem matrimonii. Primus est propagatio, et continuatio speciei, quod est bonum commune. Alius est mutuum obsequium, et communicatio operum." SC, 2.
} 
a geração, mas também a educação da prole, que exige a convivência dos pais. O ponto é resumido por referência à Ética Nicomaqueia, Livro 8. Dos pais, recebemos três coisas: existência, alimentação e educação e isso exige que os pais formem um casal, que sejam conhecidos e vivam juntos. ${ }^{36} \mathrm{~A}$ união incerta não seria admitida mesmo naquele momento de posse comum de todas as coisas e antes da instituição da propriedade em que não haveria distinção entre o meu e o teu.

A explicação da segunda finalidade do casamento, a saber, a assistência mútua que os cônjuges devem prestar, explica-se através de uma regra de divisão de tarefas e por referência ao Livro III da Política, sendo a função do marido cuidar do exterior e a função da mulher cuidar do interior da casa. ${ }^{37}$ Embora Alonso cite constantemente Aristóteles na sua argumentação, em particular o Livro VIII da Ética Nicomaqueia, é Tomás de Aquino quem constitui, como vimos, a sua referência central. Mesmo assim, é oportuno chamar atenção para um aspecto do pensamento de Aristóteles que foi fortemente explorado por Tomás de Aquino, mas que está ausente no Speculum Coniugiorum. Trata-se da noção de amizade a qual deveria, segundo o Aquinate, reger as relações conjugais, mas que praticamente desaparece no argumento de Alonso.

Tomás justifica a necessidade da união entre os cônjuges com base na condição humana animal, ou melhor, nas fraquezas que os seres humanos possuem quando comparados com os outros animais. O ser humano seria a espécie mais frágil e mais dependente dos cuidados prestados pelos pais

${ }_{36}$ "Sic Aristoteles ait. A parentibus tria recipimus. Esse, nutrimentum, et doctrinam. Filius autem non posset educari, nisi haberet derminatos parentes. Sic videtur quod de inclinatione naturae sit, quod matrimonium sit vnius ad vnam, et non vnius ad plures (sicut in politica Socratica, matrimonium et Platonica, vt Aristoteles refert). Et requiritur quod isti determati parentes sint astricti, et ligati, vt conuenienter efficiatur educatio prolis.» SC, 5 .

37 «Secundus finis matrimonii est mutuum obsequium a coniugibus sibi inuicem in rebus domesticis impendendum: ad quod ratio naturalis inclinat. Nam sicut ratio naturalis docet vt homines cohabitent in politia: quia nemo sibi sufficit in omnibus quae sunt ad vitam: ita hominem animal politicum vocamus naturaliter, quia adiacet vnicuique particula boni alterius, vt dicitur tertio politicorum, at in operibus quae pertinent ad consevationem vitae, quaedam sunt opera, quae conuenienter fiunt per viros, quaedam per mulieres: ideo associatio vtriusque et quantum ad mutuam communicationem operum, est de inclinatione naturali.» SC, 5. 
e esses, tanto para a alimentação como para a educação. Isso certamente justificaria a necessidade da presença dos pais por um longo período de tempo com seus filhos. No entanto, essa dependência ainda não seria suficiente para garantir um dos pilares básicos do casamento, a saber, a sua indissolubilidade. Para explicar essa característica, Tomás recorre a dois tipos de argumentos muito diferentes. Primeiramente, ele justifica a fidelidade que a mulher deve ao marido, argumentando que a infidelidade feminina levaria à incerteza do pai sobre a sua prole, o que levaria os pais a não se apegarem aos filhos. A certeza da paternidade, por outro lado, inclinaria os pais a ficar com seus filhos, pois veriam neles uma parte de si mesmos e, quando investissem na alimentação e educação dos filhos, investiriam também na duração do casamento.

Esse mesmo argumento não poderia ser usado no caso das esposas, porque essas não necessitam da fidelidade masculina para saber quem são seus filhos. Além disso, se o único problema a ser resolvido fosse a certeza da paternidade, então não haveria obstáculos à união de um homem com várias mulheres. Perante tais dificuldades, Tomás recorre a um argumento de outra ordem. Ele o formulou em termos de justiça natural, isto é, em termos das obrigações que os cônjuges devem uns aos outros e que se exprimem através das noções de igualdade e de apoio mútuo. Entre marido e mulher, diz Tomás de Aquino, existe uma espécie de amizade conjugal que se baseia em algo que é característico de verdadeiras formas de amizade, isto é, a amizade só é possível entre iguais. As amizades por interesse são formas de amizade que só derivam umas das outras e implicam a relegação do referido amigo para um mero meio de alcançar algo. Só aqueles que se percebem como iguais são verdadeiros amigos. Assim, se um homem fosse apegado a mulheres diferentes para ter filhos, diz Tomás, criar-se-ia uma desigualdade entre os cônjuges, pois as esposas não ocupariam adequadamente a posição de esposas, mas de servas..$^{38} \mathrm{E}$, como haveria mais de uma esposa, haveria também

${ }_{38}$ «Amicitia in quadam aequalitate consistit. Si igitur mulieri non licet habere plures viros, quia hoc est contra certitudinem prolis; liceret autem viro habere plures uxores: non esset liberalis 
uma relação de competição entre elas por recursos e pelo marido. Um argumento mais ou menos semelhante também se aplicaria se o marido pudesse pedir o divórcio. Se um homem tomasse uma esposa quando ela era jovem, quando a beleza e a fecundidade estavam presentes e, se quando ela tivesse atingido uma idade mais avançada, ele tivesse se afastado dela, então ele teria agido contra a equidade natural ou teria tomado a esposa como um meio e não como uma igual? Em outras palavras, agindo assim, o homem vai contra a amizade que deve regular a vida do casal. ${ }^{39}$

\section{Considerações finais}

Nosso objetivo nessa rápida apresentação foi duplo. Primeiramente, buscamos traçar algumas teses que devem, aos nossos olhos, servir de balizas para entender o contexto no qual os debates sobre o casamento no Novo Mundo foram travados. Em segundo lugar, buscamos chamar atenção para o modo como a autoridade de Aristóteles foi reivindicada por Alonso de la Vera Cruz para fundamentar a natureza do casamento, tanto entre católicos quanto entre infiéis. Vimos ainda que, a despeito das referências ao pensador grego, as teses aristotélicas foram apresentadas seguindo, em última instância, a interpretação de Tomás de Aquino.

\section{Referências}

Apologia pro Paulistis (1684). Transcrição C. A. M. R. Zeron. Tradução R. Ruiz. Clio: Revista de Pesquisa Histórica, [Recife], n. 26-2, p. 363-416, 2008. Aspe, V. Las consequencias del Homo est naturaliter magis animal coniugale quam politicum en el Speculum de Alonso de la Vera Cruz. In: Gómes, A. V.

amicitia uxoris ad virum, sed quasi servilis. Et haec etiam ratio experimento comprobatur: quia apud viros habentes plures uxores, uxores quasi ancillariter habentur.» TomÁs de Aquino, Suma contra Gentiles, III, 124.

39 Para uma apresentação mais detida do argumento em Tomás de Aquino, veja-se: Witte Jr, J. From Sacrament to Contract. Marriage, Religion, and Law in the Western Tradition. Louisville: Westminster John Knox Press, 2. ed., 2012, p. 82-87. 
(org.). Fray Alonso de la Vera Cruz: universitário, humanista, científico y republicano. Ciudad Universtaria: Universidad Nacional Autonoma de México, 2009. p. 143-153. https://doi.org/10.21898/dia.v53i61.279

Assimakópulos, A.; Contreras, S. Matrimonio y derecho natural e Alonso de Veracruz (1507-1584). Revista de Estudos Históricos-Jurídicos, Valparaíso, n. 39, p. 173-193, ago. 2017. https://doi.org/10.4067/s0716-54552017000100173 Beuchot, M. Perfil del pensamiento filosófico de fray Alonso de la Vera Cruz. Nova Tellus, [s.l.], n. 29, p. 201-214, 2011. https://doi.org/10.19130/iifl. nt.2011.29.2.393

Biblia Sacra Vulgata. Stuttgart: Deutsche Bibelgesellschaft, 2005.

Boxer, C. R. A Igreja militante e a expansão ibérica: 1440-1770. Tradução Vera Maria Pereira. São Paulo: Companhia das Letras, 2007.

Burrus, E. J. The Writtings of Alonzo de la Vera Cruz: The Original Texts with English Translation. St. Louis: Jesuit Historical Institute, 1968-1976, 5 V.

Cairns, J. W.; Plessis, P. J. (ed.). The Creation of the lus Commune. From Casus to Regulae. Edinburgh: Edinburgh University Press, 2012. https://doi. org/10.3366/elr.2012.0085

Calafate, P. Estudo Introdutório I - A guerra justa igualdade natural dos povos: os debates ético-jurídicos sobre os direitos da pessoa humana. In: Calafate, P. (org.). A Escola Ibérica da Paz nas Universidades de Coimbra e Évora (século XVI). Coimbra: Almedina, 2015. p. 17- 47. 2 v. https://doi.org/10.15448/19806736.2014.1.18283

Campos, Y. E. M. La ley natural y el matrimonio en el Espejo de los cónyuges de Alonso de la Vera Cruz: La problemática sobre la ley natural y la diversidad cultural en los albores de la nation mexicana. Tese (Doutorado em Filosofia) - Faculdade de Filosofia, Universidad Panamericana, Cidade do México, 2010. https://doi.org/10.21898/dia.v53i61.279

Castelnau-l'Estoile, C. Operários de uma vinha estéril. Os jesuítas e a conversão dos índios no Brasil - 1580-1620. Tradução de Ilka Stern Cohen. São Paulo: Edusc, 2006.

Cunha, M. S. A Europa que atravessa o Atlântico (1500-1625). In: Fragoso, J.; Gouvêa, M. F. O Brasil Colonial, 1443-1580. Rio de Janeiro: Civilização Brasileira, c2014. p. 271-314. v. 1.

de la Vera Cruz, A. Speculum conjugiorum, Mediolanum, 1599. 
de la Vera Cruz, A. Sobre el Dominio de los indios y la Guerra Justa. Edición, introducción y notas R. H. Correa. Ciudad Universitaria: UNAM, 2004. https:// doi.org/10.19130/iifl.nt.2008.26.2.286

Decock, W. Rumo a uma ciência do direito jesuítica. Revista do Instituto Histórico Geográfico do Rio Grande do Sul, Porto Alegre, n. 151, p. 73-110, 2016. https://doi.org/10.29289/259453942018v28s1059

Decock, W. Theologians and Contract Law: The Moral Transformation of the lus Commune (ca. 1500-1650). Leiden: Martinus Nijhoff Publishers, 2013. https://doi.org/10.1163/15718190-08134p20

Diaz, G. D. Hombres y documentos de la filosofía española. Madrid: Consejo Superior de Investigaciones Científicas, v. 1, p. 198-202, 1998. https://doi. org/10.1163/18756735-90000323

Fontana, L. A. B. Matrimonio, familia y divorcio. Actualidad de los principios del derecho matrimonial y familiar según el Speculum Coniugiorum de Fray Alonso de la Vera Cruz. Tese (Doctorado en Letras) - Universidad Nacional Autónoma de México, 2010. https://doi.org/10.19130/iifl.nt.2010.28.2.356

Fontana, L. B. El "Speculum Coniugiorum" de fray Alonso de la Vera Cruz. Traducción y comentarios. Tese (Mestrado en Letras Clássicas) - Universidad Nacional Autónoma de México, Ciudad do México, 2006. https://doi. org/10.19130/iifl.nt.2010.28.2.356

Goering, J. The Internal Forum and the Literature of Penance and Confession. In: Hartmann, W; Pennington, K. (ed.). The History of Medieval Canon Law in the Classical Period, 1140-1234: From Gratian to the Decretals of Pope Gregory IX. Washington: Catholic University of America Press, 2008, p. 379428. https://doi.org/10.2307/j.ctt285355.16

Gordley, J. The Philosophical Origins of Modern Contract Doctrine. Oxford: Clarendon Press, 1993.

Heredia, R. Coacción para la fe. Una aproximación al tratado De dominio infidelium et iusto bello de fray Alonso de la Vera Cruz. Tópicos v. 34, p. 157208, 2008. https://doi.org/10.2307/j.ctv6mtc1g.7

Hornaert, E. et al. História da Igreja no Brasil. Ensaio de interpretação a partir do povo. Primeira época: período colonial. 5. ed. Petrópolis: Vozes, 2008, p. 143.

Medina, Y. Lei natural y matrimonio en el Speculum de Alonso de la Vera Cruz. In: Gómez, A. V. (org.). Fray Alonso de la Vera Cruz: universitário, humanista, científico y republicano. Ciudad Universitaria: Universidad Nacional Autónoma de México, 2009, p. 125-142. https://doi.org/10.21898/dia.v53i61.279 
Merêa, P. Sobre a origem do poder civil: Estudos sobre o pensamento político e jurídico dos séculos XVI e XVII. Coimbra: Edições Tenacitas, 2003.

Ordeñana, J. G. El "speculum coniugiorum" de Alonso de la Veracruz y la inculturación del matriminio canónico en México. Ius canonicum, v. 39, p. 619-32, 1999.

Ponce, C. La liberdad en el Speculum de Alonso de la Vera Cruz. In: Gómez, A. V. (org). Fray Alonso de la Vera Cruz: universitário, humanista, científico y republicano. Ciudad Universitaria: Universidad Nacional Autónoma de México, 2009, p. 155-171. https://doi.org/10.21898/dia.v53i61.279

Prodi, P. Una historia de la justicia. De la pluralidad de fueros al dualismo moderno entre conciencia y derecho. Traducido por L. P. López. Buenos Aires: Katz Editores, 2008.

Sevilla, F. C. F. Análisis socio-bibliográfico de fray Alonso de Veracruz, OSA (Caspueñas - Guadalajara, España - 1507 / México, Nueva España, 1584). Anuario Jurídico y Económico Escurialense, v. 41, p. 831-850, 2008.

Tomás de Aquino. Opera Omnia. Romae: Editio Leonina, diversos anos.

Vicente Pereña, L. Carta Magna de los Indios. Salamanca: Universidad Pontificia de Salamanca, 1996.

Vicente Pereña, L. Mission de España en America 1540-1560. Madrid: Consejo Superior de Investigaciones Científicas, 1956.

Waelkens, L. Amne Adverso: Roman Legal Heritage in European Culture. Leuven: Leuven University Press, 2015. https://doi.org/10.4467/20844131 ks.16.029.6329

Witte JÚNIOR, J. From Sacrament to Contract. Marriage, Religion, and Law in the Western Tradition. 2. ed. Louisville: Westminster John Knox Press, 2012. https://doi.org/10.1017/jlr.2015.13

Zeron, C. A. M. R. Linha de fé. A Companhia de Jesus e a escravidão no processo de formação da sociedade colonial (Brasil, séculos XVI e XVII). Tradução de Antônio de Padua Danesi. São Paulo: Edusp, 2011.

Zeron, C. A. R. M. Interpretações de Francisco Suárez na Apologia pro paulistis (1684). In: Mezan Algranti, L. M.; Torres Megiani, A. P. (org.). O Império por escrito. Formas de transmissão da cultura letrada no mundo ibérico (séc. XVI-XIX). São Paulo: Alameda, 2009. 


\section{Endereço postal}

UFRGS - Instituto de Filosofia e Ciências Humanas

Av. Bento Gonçalves, 9500 - Agronomia,

Porto Alegre - RS, CEP: 91509-900 